\title{
THE IMPACT OF FEASIBILITY STUDY ON PALESTINIAN SMALL INVESTMENT PROJECTS
}

Khalid Mohammad Hasan Sweis, Palestine Technical University, Kadoorie, Tulkarm, Palestine Tamer Bahjat Sabri, Palestine Technical University, Kadoorie, Tulkarm, Palestine Qadri Kamal Alzaghal, Palestine Technical University, Kadoorie, Tulkarm, Palestine Samaa Baker Mssis, Palestine Technical University, Kadoorie, Tulkarm, Palestine Manal Maan Awartani, Palestine Technical University, Kadoorie, Tulkarm, Palestine

\author{
dx.doi.org/10.18374/IJBR-19-3.7
}

\begin{abstract}
The study is intended to find out the impact of the economic feasibility study on small Palestinian investment projects. A descriptive analytical methodology has been adopted using a questionnaire to achieve the various objectives of the study. The sample size of the study includes (163 persons) representing small entrepreneurs located in the Governorate of Tulkarm. The most important result of the study shows that many respondents believe that the feasibility consultancy offices do not have the required expertise and experience and are mostly unaware of the importance of the feasibility study as well as its high costs. One of the most important recommendations of the study relates to the need for training the staff of consultancy offices to be fully capable of preparing economic feasibility studies, showing their importance, and working hard to reduce the cost of preparing these studies.
\end{abstract}

Keywords: economic feasibility, investment, Palestine, small enterprises. 